\title{
Correlation between the Morphology and Performance Enhancement of ZnO Hierarchical Flower Photoanodes in Quasi-Solid Dye-Sensitized Solar Cells
}

\author{
Chao Zhu, Yantao Shi, Chun Cheng, Lin Wang, Kwok Kwong Fung, and Ning Wang \\ Department of Physics and the William Mong Institute of Nano Science and Technology, \\ The Hong Kong University of Science and Technology, Hong Kong \\ Correspondence should be addressed to Ning Wang, phwang@ust.hk
}

Received 26 April 2012; Accepted 19 August 2012

Academic Editor: Jianguang Jia

Copyright ( $) 2012$ Chao Zhu et al. This is an open access article distributed under the Creative Commons Attribution License, which permits unrestricted use, distribution, and reproduction in any medium, provided the original work is properly cited.

\begin{abstract}
We report an effective method for mass production of $\mathrm{ZnO}$ hierarchical flowers (HFs) that are constructed by interlaced single crystalline $\mathrm{ZnO}$ nanosheets with dominant surfaces of $\{11 \overline{2} 0\}$ and $\{1 \overline{1} 00\}$. The size of ZnO HFs, thickness and parking density of the nanosheets, and HF inner porosity can be tuned by changing the synthesis conditions. The HFs containing porous inner structures showed an excellent performance as the photoanode material in quasi-solid (using polymer gel electrolytes) dyesensitized solar cells (DSCs) because of their superior optical and electrical properties. The high current density $\left(10.26 \mathrm{~mA} \mathrm{~cm}^{-2}\right)$ and efficiency $(4.93 \%)$ of the HF-based DSCs indicate a great potential for the development of high-efficient quasi-solid DSCs.
\end{abstract}

\section{Introduction}

In the past two decades, porous photoanodes have been intensively studied as one of the key components used to enhance the performance of dye-sensitized solar cells (DSCs) [1-3]. Conventionally, different sizes of particles such as nanoparticles $(\sim 20 \mathrm{~nm})$ and submicron particles $(\sim 200 \mathrm{~nm})$ are employed to construct a double-layered photoanode structure with aims to guarantee dye-loading and improve light-scattering efficiency, respectively [1]. However, the total surface area of this kind of photoanodes is inevitably reduced because of the larger size of particles introduced. In recent years, photoanodes constructed by hierarchical structured materials have been found to effectively increase the photoanode efficiency. This is because, with the advantages of nanosized primary particles and the submicron-sized secondary aggregates, the hierarchical photoanodes can offer a large surface area for sufficient dye-loading and in the meantime ensure the efficient lightscattering [4]. Recently, most research work have focused on nanostructured $\mathrm{TiO}_{2}$ as the photoanodes to which the dye is bound. However, good results have also been obtained using other materials such as $\mathrm{ZnO}, \mathrm{SnO}_{2}$, and $\mathrm{Nb}_{2} \mathrm{O}_{5}[5-16]$. $\mathrm{ZnO}$ is an attractive photoanode material because its electron mobility is much higher than that of $\mathrm{TiO}_{2}$, while the conduction band edges of both materials locate at approximately the same level. In addition, $\mathrm{ZnO}$ shows better flexibilities in synthesis process and morphology control. $\mathrm{ZnO}$ hierarchical photoanode structures based on nanocrystalline aggregates, flower-like spheres, and dendritic nanowires have been reported in recent years [17-21].

To increase the conversion efficiency of the DSCs, both optical (dye loading and light scattering) and electrical transport properties need to be optimized. For example, by improving the light-harvesting ability of $\mathrm{ZnO}$ nanostructured photoanodes, a high conversion efficiency of 5.4\% (using polydispersed $\mathrm{ZnO}$ aggregates and liquid electrolyte) has been achieved by Zhang et al. in 2008 [22]. ZnO nanowires have been suggested to be ideal nanostructures to provide direct pathways for electron collection and transportation [23-27]. However, the insufficiency of the internal active surface area of $\mathrm{ZnO}$ nanowire nanostructures always limits their energy conversion performance [26]. Having superior optical and electrical properties, in recent years, $\mathrm{ZnO}$ hierarchical nanostructures have been considered as an emerging photoanode material for developing future 
high efficient DSCs. Recently, we developed a facile direct precipitation method for fabricating a novel flower-like $\mathrm{ZnO}$ hierarchical structure from aqueous solution at room temperature [28]. These $\mathrm{ZnO}$ flowers were mainly constructed by interlaced monocrystalline $\mathrm{ZnO}$ nanosheets. The photoanodes made from these flowers showed both superior optical performance and excellent electrical properties for quasisolid (using polymer gel electrolyte) DSCs. The electron diffusion coefficient in this kind of photoanodes was nearly one order of magnitude higher than that in conventional nanoparticle- (NP-) based photoanodes and thus largely improved the DSCs photovoltaic performance. The stability of DSCs is another important factor for practical application. Problems such as leakage, volatilization, and corrosion have been regarded as the critical factors limiting the long-term performance of the DSCs assembled using liquid electrolytes. Instead, quasi-solid electrolytes [29] can alleviate these problems and they is also suitable for flexible DSCs with varied geometries although the conversion efficiency of the quasi-solid DSCs are normally low due to the slow ionic transport in quasi-solid electrolytes [30].

In the paper, we report a systematic investigation of the morphology variations (e.g., flower size, thickness, and parking density of the nanosheets, inner structures, etc.) of the $\mathrm{ZnO}$ hierarchical flowers (HFs) formed under different experimental conditions and the relationships between flowers' morphologies and their DSCs' performances. The $\mathrm{ZnO} \mathrm{HFs}$ possessing porous structures showed excellent performance due to their excellent capabilities in lightharvesting and charge transport and thus resulted in a high current density of $10.26 \mathrm{~mA} \mathrm{~cm}^{-2}$ and overall energy conversion efficiency up to $4.93 \%$ in the PEO-based polymer gel quasi-solid electrolyte system.

\section{Experiments}

2.1. Synthesis of $\mathrm{ZnO} H F$ s. ZnO HFs containing hierarchical structures were synthesized by a direct precipitation method, and all reactants were used without further purification. Firstly, zinc nitrate hexahydrate and sodium hydroxide were dissolved by $1 \mathrm{~L}$ distilled water separately. Then the zinc nitrate hexahydrate aqueous solution was added into the sodium hydroxide aqueous solution continuously with a flow rate of about $20 \mathrm{~mL} \mathrm{~s}^{-1}$. After stirring for $20 \mathrm{~min}$, the resulting white product was filtered and washed with distilled water for several times.

2.2. Assembly of the DSCs. In our experiment, in order to enhance the mechanical strength of the $\mathrm{ZnO}$ layer and the electrical connection between the $\mathrm{ZnO}$ hierarchical structures and the FTO glass electrode, the $\mathrm{ZnO}$ HFs were mixed with about $20 \mathrm{wt} \%$ of $\mathrm{ZnO}$ nanoparticles $(20 \mathrm{~nm}$ in diameter). The $\mathrm{ZnO}$ paste was prepared by mixing $0.5 \mathrm{~g} \mathrm{ZnO}$ power $(0.4 \mathrm{~g} \mathrm{ZnO} \mathrm{HFs} \mathrm{and} 0.1 \mathrm{~g} \mathrm{ZnO}$ nanoparticles) with $0.75 \mathrm{~g}$ absolute alcohol and $0.5 \mathrm{~g}$ distilled water, then followed by ultrasonic treatment until the particles were dispersed homogeneously. Doctor blade technique was used to prepare the porous $\mathrm{ZnO}$ layers with their thickness being controlled by a $120 \mu \mathrm{m}$ adhesive tape. The $\mathrm{ZnO}$ photoanode was sintered at $200^{\circ} \mathrm{C}$ for $1.5 \mathrm{~h}$. After cooling down to $100^{\circ} \mathrm{C}$, the $\mathrm{ZnO}$ films were sensitized in $0.3 \mathrm{mM}$ N719 absolute ethanol solution at $50^{\circ} \mathrm{C}$ for $60 \mathrm{~min}$, followed by cleaning with absolute ethanol. A chemically platinized conductive glass served as the counter electrode. The polymer gel electrolyte in this study was a quasi-solid mixture containing $0.1 \mathrm{M} \mathrm{LiI}, 0.1 \mathrm{M}$ $\mathrm{I}_{2}, 0.6 \mathrm{M} \mathrm{1,2-dimethyl-3-propyl} \mathrm{imidazolium} \mathrm{iodide,} 0.45 \mathrm{M}$ $\mathrm{N}$-methyl-benzimidazole in 3-methoxypropionitrile solvent, and $15 \%$ (weight ratio) gelator (PEO, $\mathrm{M}_{w}=2 \times 10^{6} \mathrm{~g} \mathrm{~mol}^{-1}$ ). When assembling DSCs, a sensitized $\mathrm{ZnO}$ photoanode and a counter electrode sandwiching the polymer gel electrolyte were fixed by two clips, and an adhesive tape with a thickness of $50 \mu \mathrm{m}$ is used to avoid the contact between two electrodes. Finally, the DSCs were baked at $90^{\circ} \mathrm{C}$ for $20 \mathrm{~min}$ to ensure the polymer gel electrolyte can penetrate into the nanoporous electrodes.

2.3. Characterization. The morphologies of the $\mathrm{ZnO} \mathrm{HFs}$ and the photoanodes were characterized by scanning electron microscopy (Philips XL30) and high-resolution transmission electron microscopy (JEOL, JEM-2010F). The diffuse-reflectance spectra were characterized with a UV-vis spectrophotometer (Lambda 20). BET surface area of the samples was characterized using Coulter SA 3100 surface area analyzer. The photovoltaic performances of the DSCs were measured by KEITHLEY 2420 source-meter under AM 1.5, $100 \mathrm{~mW}$ illumination (Xenon lamp solar simulator, Newport, Class A).

\section{Results and Discussions}

3.1. The Structure and Performance of $\mathrm{ZnO}$ HFs in DSCs. In this work, we employed the direct precipitation method [28] to synthesize the $\mathrm{ZnO} \mathrm{HF}$ reference sample (sample 1). As shown in Figure 1(a), the sizes of the HFs in sample 1 are uniform and most of the spherical HFs possess diameters in the range of 5-6 $\mu \mathrm{m}$. The enlarged image in Figure 1(b) reveals that the HF is constructed with densely interlaced nanosheets. In addition to the $\{1 \overline{1} 00\}$ dominated planes we reported in a previous publication [28], \{1120\} planes have also been found in $\mathrm{ZnO}$ nanosheets (see Figure S.1). Figure 1(c) presents a typical morphology of the inner parts of $\mathrm{ZnO}$ HFs by breaking the HFs through ultrasonic treatment. Obviously, the core of the HF in sample 1 is nearly solid. As shown in the enlarged SEM images in Figure S.2a, the core structure consists of tiny closely stacked nanoplates. The HFs from sample 1 were then assembled into quasisolid DSCs and the current density $(J)$-voltage $(V)$ curve was measured under illumination of AM $1.5,100 \mathrm{~mW} \mathrm{~cm}{ }^{-2}$ simulated sunlight. As shown in Figure 1(d) and summarized in Table 1, the DSCs based on sample 1 can generate a short-circuit density (JSC) of $8.23 \mathrm{~mA} \mathrm{~cm}^{-2}$ and an opencircuit voltage $\left(V_{\mathrm{OC}}\right)$ of $0.688 \mathrm{~V}$, resulting in a conversion efficiency $(\eta)$ of $3.92 \%$. We believe that because of their wellcrystallized nanosheets and the microsized particles, the HFbased photoanodes can efficiently minimize massive electron 


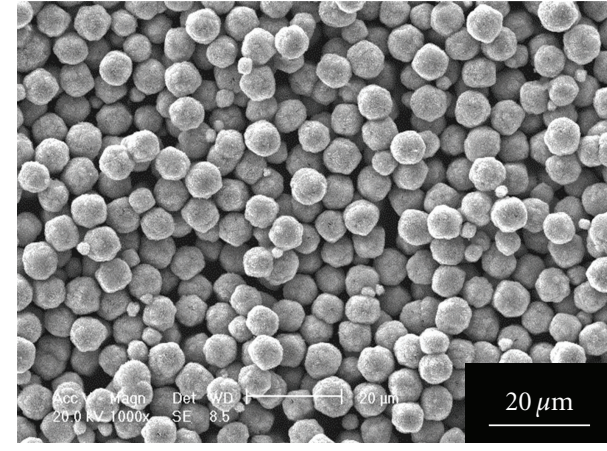

(a)

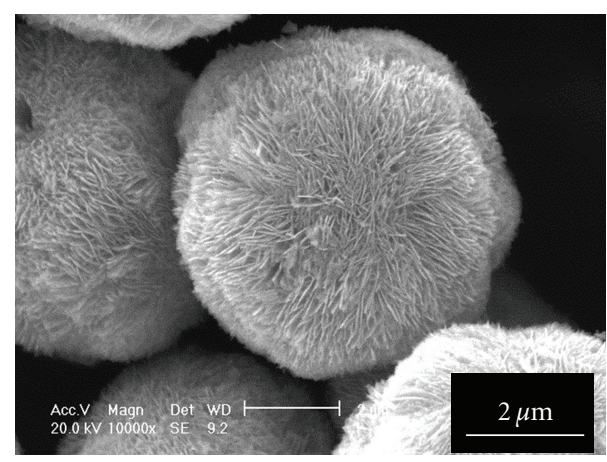

(b)

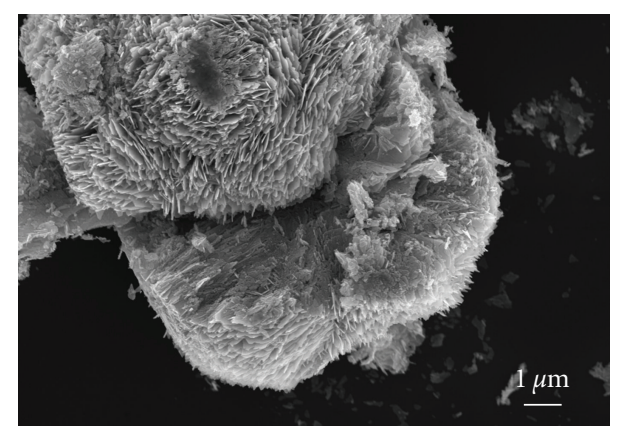

(c)

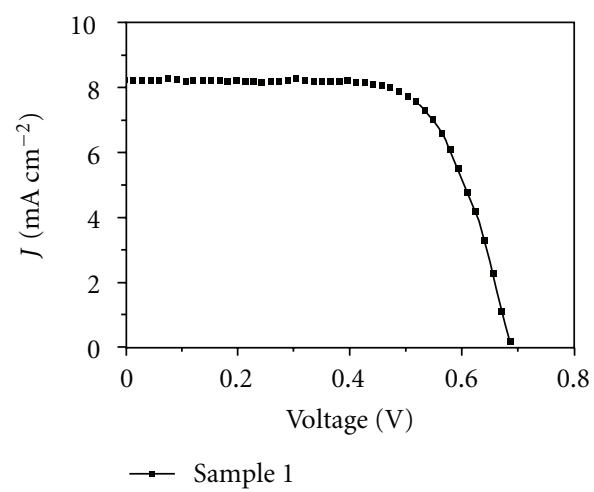

(d)

Figure 1: (a), (b), and (c) SEM images of the HFs in sample 1. (d) $J-V$ curve of the DSCs based on sample 1 . hoping which normally happens in nanoparticle basedphotoanodes [3]. However, the low Brunauer-Emmett-Teller (BET) specific internal area $\left(18.82 \mathrm{~m}^{2} \mathrm{~g}^{-1}\right)$ of this sample reveals that the solid core of the HFs is not utilized since this will cause insufficient adsorption of the dye molecules.

\subsection{Tuning Morphologies by Changing Synthetic Conditions}

3.2.1. Reactant Concentrations. Comparing with sample 1, we observed obvious changes on the HF morphology by increasing the concentrations of $\mathrm{NaOH}$ and $\mathrm{Zn}\left(\mathrm{NO}_{3}\right)_{2}$ solutions (keeping the ratio of $\mathrm{NaOH}$ and $\mathrm{Zn}\left(\mathrm{NO}_{3}\right)_{2}$ unchanged). As shown in Figure 2(a), the size of the HFs became small ( 2 to $4 \mu \mathrm{m}$ ) and nonuniform when the reactant concentration was doubled. The interlaced nanosheets become loosely packed (see Figure 2(b)). In the inner parts of the HFs, we observed that the density of the stacked nanoplates decreased (see Figure S.2b), leading to a porous structure as presented in Figure 2(c). On the other hand, the morphology of the HFs formed in a dilute solution (e.g., 0.5 time of the concentration used for sample 1) did not show significant changes in comparison with sample 1 (see Figure S.3a).

By decreasing the concentration of $\mathrm{Zn}\left(\mathrm{NO}_{3}\right)_{2}$ (e.g., from $0.1 \mathrm{M}$ to $0.05 \mathrm{M}$, while keeping $\mathrm{NaOH}$ concentration $(0.5 \mathrm{M})$ unchanged) a large number of irregular HFs (see Figure 2(d)) were obtained. The typical morphology of the HFs in this sample is illustrated in Figure 2(e), from which different structures have been observed in comparison with sample 1. Firstly, $\mathrm{ZnO}$ nano ribbons forming thick bundles extend out from the HFs. Secondly, the nanosheets that construct the HFs become much thicker than those in sample 1. Thirdly, substructures such as small nanorods and nanoparticles form on the surfaces of the HF nanosheets. The core of the HFs is solid, similar to that in sample 1 (Figure 2(f)). We have confirmed that by increasing the concentration of $\mathrm{Zn}\left(\mathrm{NO}_{3}\right)_{2}$ (e.g., from $0.1 \mathrm{M}$ to $0.15 \mathrm{M}$ ); however, the morphology of the HFs was not significantly changed. Instead, a small amount of by-products such as fan-shaped $\mathrm{ZnO}$ structures (see Figure S.3b) have been generated.

3.2.2. Temperature Effects. By increasing the reaction temperature and keeping other synthesis conditions unchanged (same as sample 1), the size of the HFs decreased $(4 \sim 5 \mu \mathrm{m}$ at $40^{\circ} \mathrm{C}$ ) as shown in Figure $2(\mathrm{~g})$, and the thickness of the nanosheets increased (Figure 2(h)). The nanosheets contain more defects. Similar to samples 1 and 3 , the inner parts of the HFs are solid (Figure 2(i)). Further increasing of the reaction temperature to $60^{\circ} \mathrm{C}$, the products are no longer spherical HFs, instead small-sized ( 1 to $2 \mu \mathrm{m}$ ) star-like (see Figure S.3c) products were obtained.

3.3. The Photovoltaic Performance of $Z n O$ HFs. To investigate the performance variation caused by different HF morphologies and synthesis conditions, four kinds of samples were selected and assembled into DSCs for further study. The detailed synthesis conditions for synthesizing the HFs 


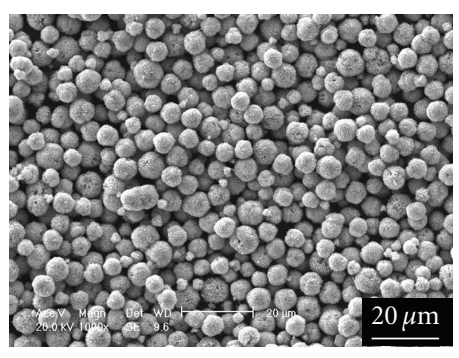

(a)

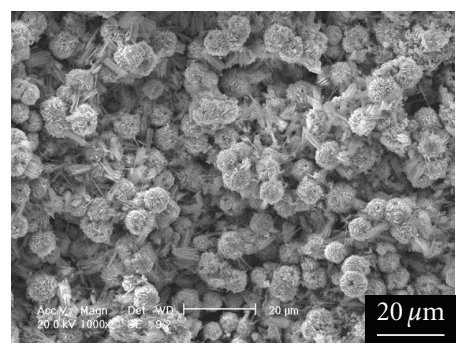

(d)

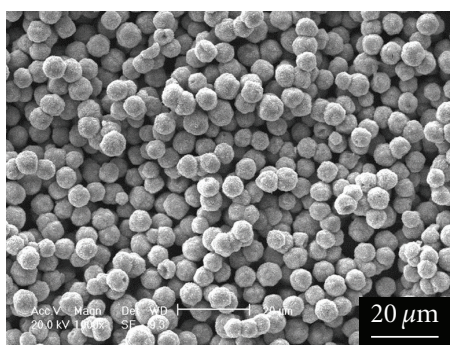

(g)

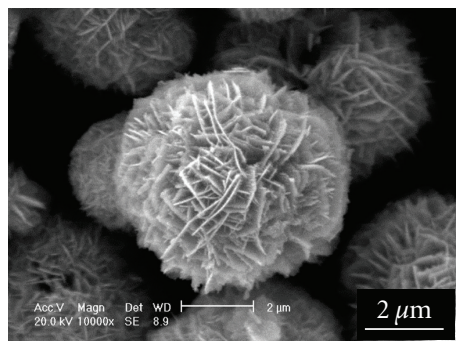

(b)

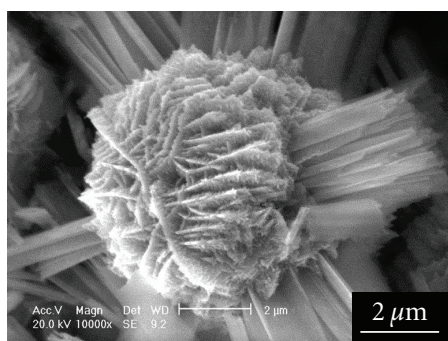

(e)

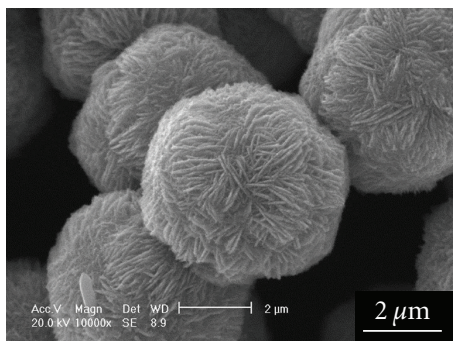

(h)

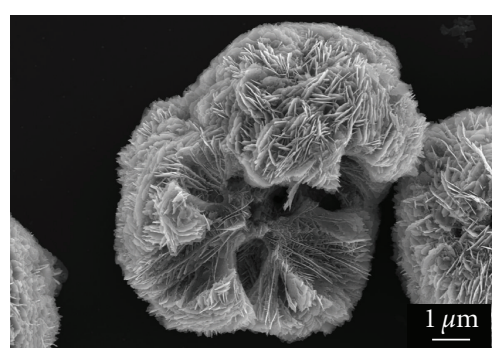

(c)

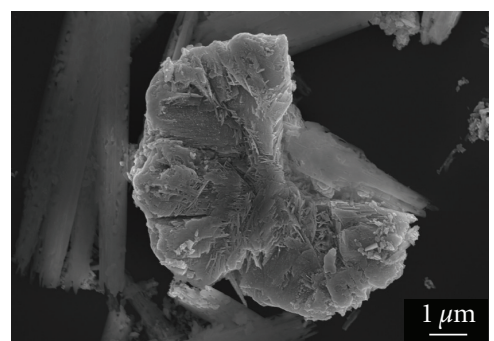

(f)

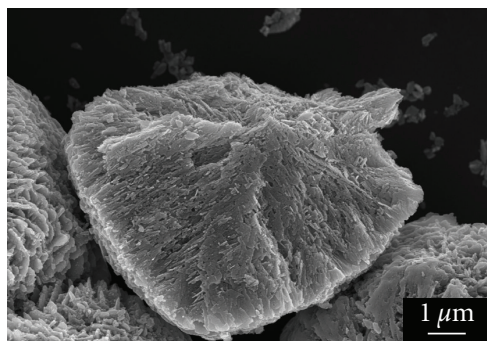

(i)

Figure 2: SEM images of $\mathrm{ZnO} H F$ s synthesized with different synthetic parameters: (a), (b), and (c) $\mathrm{NaOH}: 1.0 \mathrm{M}, \mathrm{Zn}(\mathrm{NO})_{2}: 0.2 \mathrm{M}$, temperature: $20^{\circ} \mathrm{C}$; (d), (e), and (f) $\mathrm{NaOH}: 0.5 \mathrm{M}, \mathrm{Zn}\left(\mathrm{NO}_{3}\right)_{2}: 0.05 \mathrm{M}$, temperature: $20^{\circ} \mathrm{C}$; (g), (h), and (i) $\mathrm{NaOH}: 0.5 \mathrm{M}, \mathrm{Zn}\left(\mathrm{NO}_{3}\right)_{2}: 0.1 \mathrm{M}$, temperature: $40^{\circ} \mathrm{C}$.

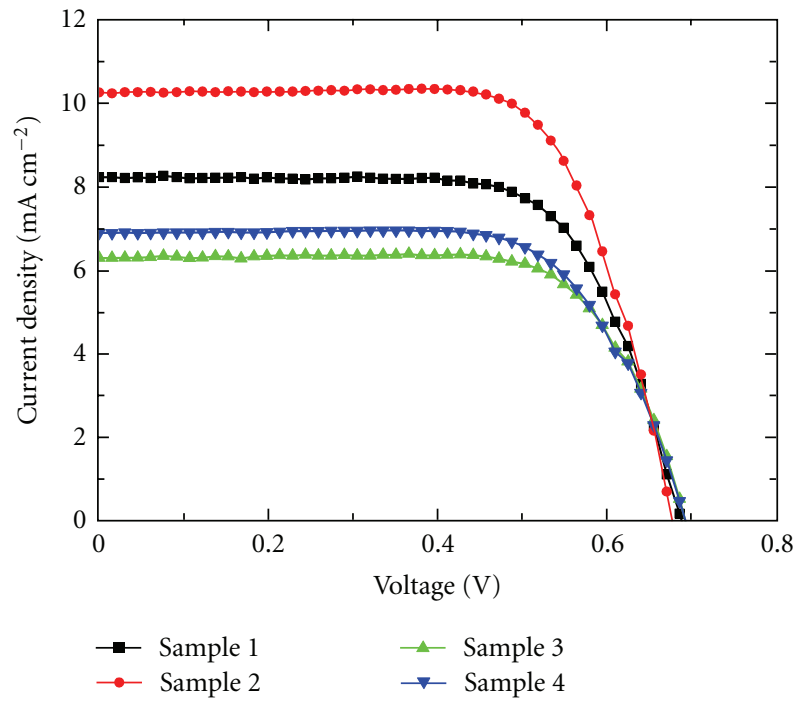

Figure 3: $J-V$ curves of the DSCs based on the four samples. are summarized in Table 2. Figure 3 shows the $J-V$ curves of these four DSCs and the corresponding parameters are summarized in Table 3 . Since there are only insignificant differences in the open-circuit voltage $\left(V_{\mathrm{OC}}\right)$ and fill factor $(\mathrm{FF})$, the differences in these DSCs conversion efficiencies are mainly due to the changes of the short-circuit densities $\left(J_{\mathrm{SC}}\right)$. Obviously, the DSC based on sample 2 displays a much better photoelectric conversion capacity than the other three samples. It has a higher $J_{\mathrm{SC}}$ of $10.26 \mathrm{~mA} \mathrm{~cm}^{-2}$, and this eventually leads to a high conversion efficiency $(\eta)$ of $4.93 \%$. The performances of samples 3 and 4 are not good due to their small effective surface area in these two samples. The BET results (Table 3 ) clearly show that the specific area of sample $2\left(21.13 \mathrm{~m}^{2} \mathrm{~g}^{-1}\right)$ is higher than that of other samples. This is in good agreement with the SEM results. The extended $\mathrm{ZnO}$ bundles in sample 3 and the defective thick nanosheets in sample 4 are main factors resulting in small surface area. Although the loosely packing of nanosheets may cause some loss of internal specific area, the porous inner structure in sample 2 is believed to largely extend the total surface area. 


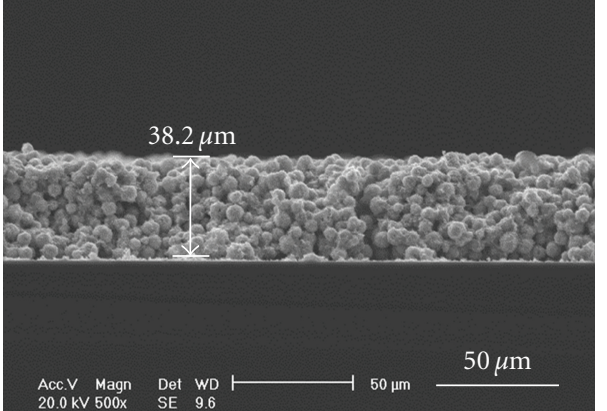

(a)

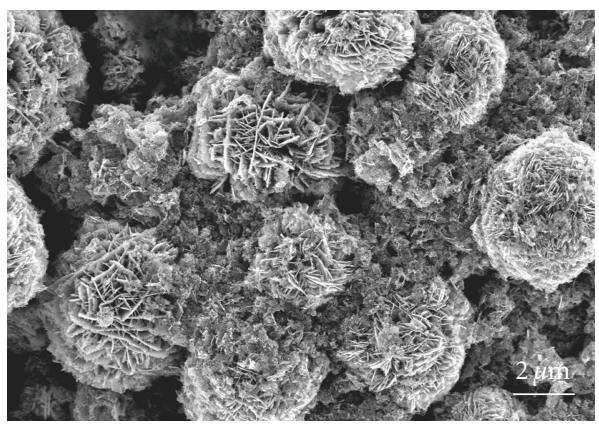

(b)

Figure 4: (a) The cross-sectional and (b) top view SEM images of the photoanode based on sample 2 .

TABLE 1: Summary of the properties and the performance of $\mathrm{ZnO}$ HF-based DSCs (sample 1).

\begin{tabular}{lccccc}
\hline $\begin{array}{c}\text { Sample } \\
(\text { DSC- })\end{array}$ & $\begin{array}{c}\text { BET } \\
\left(\mathrm{m}^{2} \mathrm{~g}^{-1}\right)\end{array}$ & $\begin{array}{c}J_{S C} \\
\left(\mathrm{~mA} \mathrm{~cm}^{-2}\right)\end{array}$ & $\begin{array}{c}V_{\mathrm{OC}} \\
(\mathrm{V})\end{array}$ & $\begin{array}{c}\mathrm{FF} \\
(\%)\end{array}$ & $\begin{array}{c}\eta \\
(\%)\end{array}$ \\
\hline 1 & 18.82 & 8.23 & 0.688 & 69.1 & 3.92 \\
\hline
\end{tabular}

TABLE 2: Synthetic parameters for different samples.

\begin{tabular}{lccc}
\hline Sample & Temperature $\left({ }^{\circ} \mathrm{C}\right)$ & $C_{\mathrm{NaOH}}(\mathrm{M})$ & $C_{\mathrm{Zn}\left(\mathrm{NO}_{3}\right)_{2}}(\mathrm{M})$ \\
\hline 1 & 20 & 0.5 & 0.1 \\
2 & 20 & 1.0 & 0.2 \\
3 & 20 & 0.5 & 0.05 \\
4 & 40 & 0.5 & 0.1 \\
\hline
\end{tabular}

3.4. Light Scattering and Absorption Capability. Figure 4(a) shows a typical morphology of the photoanode films based on sample 2. To enhance the link between HFs (see Figure 4(b)) and the mechanical strength of the photoanode films, we have added $\mathrm{ZnO}$ small particles (about $20 \mathrm{~nm}$ in diameter) into different HF samples and fabricated HF photoanode films with thicknesses of about 35.5-38.6 $\mu \mathrm{m}$. The light-scattering performances of these unsensitized photoanodes were then characterized. As shown by the solid lines in the UV-vis diffuse-reflectance spectra in Figure 5(a), all photoanodes exhibit excellent light-scattering capability. From 400 to $900 \mathrm{~nm}$, the slow decline in light reflectance of these four samples illuminates that the photoanodes can effectively prevent most of the incident light with wavelength in this range from transmitting out directly and therefore
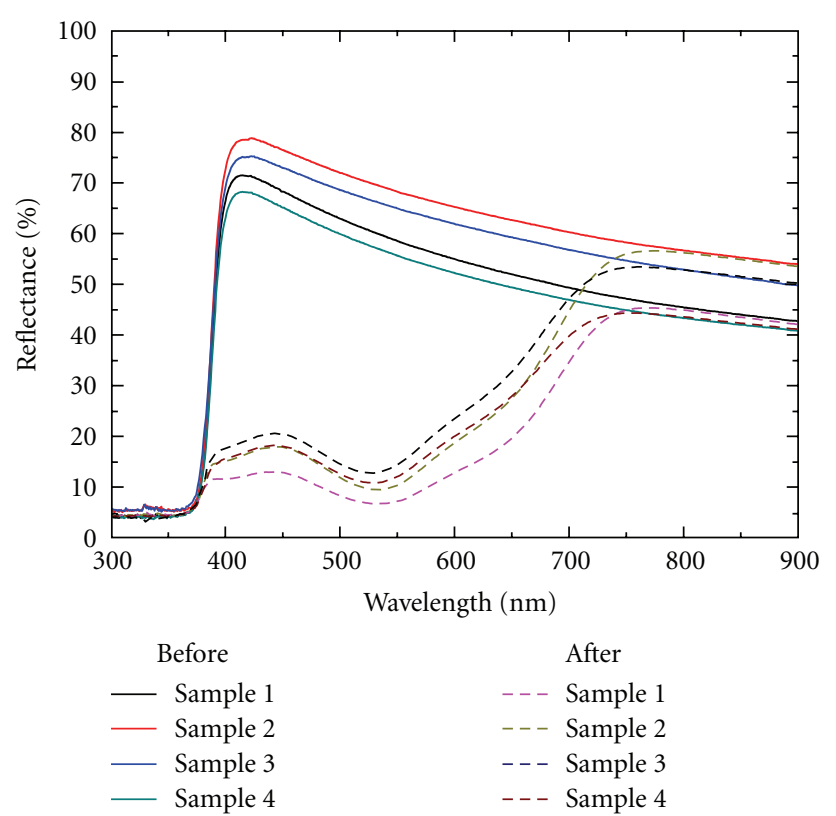

(a)

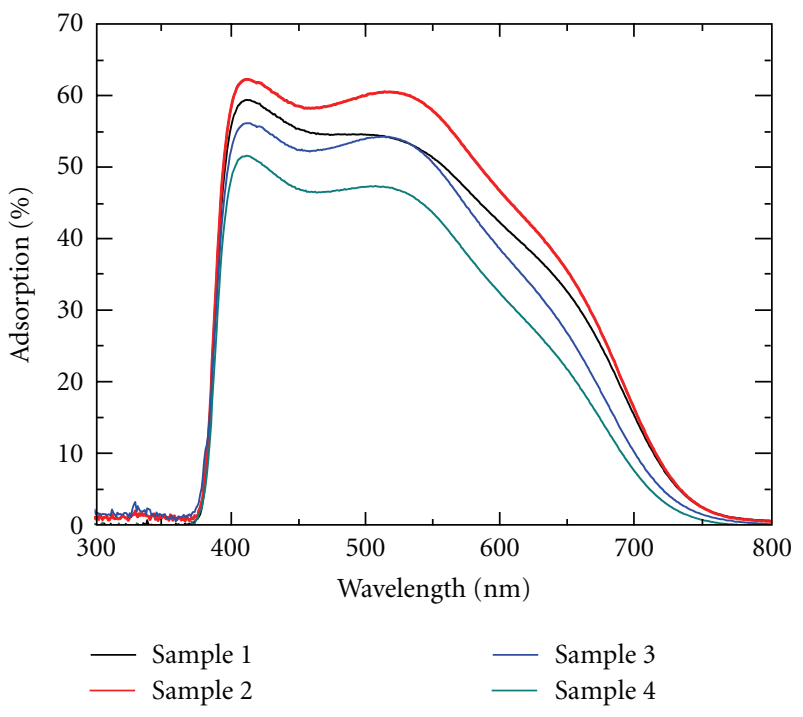

(b)

Figure 5: (a) Diffuse-reflectance spectra of photoanodes and (b) optical adsorption spectra of dye-sensitized photoanodes.

result in a high chance for photons to be captured by dye molecules. Among these four un-sensitized photoanodes, the one based on sample 2 shows the best light-scattering capability. This should be attributed to not only the smaller size $(2$ to $4 \mu \mathrm{m}$ ) of the HFs that are more comparable to the wavelength of incident light than the other three samples, but also the broad and deep channels between adjacent nanosheets which can extend the pathway into the porous inner architecture of HFs for photon localization enhancement [31, 32]. Diffuse-reflectance spectra (dashed lines) of corresponding sensitized photoanodes are also given 
TABLE 3: Property and performance of different photoanode samples in DSCs.

\begin{tabular}{lcccccc}
\hline Sample (DSC-) & BET $\left(\mathrm{m}^{2} \mathrm{~g}^{-1}\right)$ & Film thickness $(\mu \mathrm{m})$ & $J_{\mathrm{SC}}\left(\mathrm{mA} \mathrm{cm}^{-2}\right)$ & $V_{\mathrm{OC}}(\mathrm{V})$ & $\mathrm{FF}(\%)$ & $\mathrm{H}(\%)$ \\
\hline 1 & 18.82 & 35.5 & 8.23 & 0.688 & 69.1 & 3.92 \\
2 & 21.13 & 38.2 & 10.26 & 0.678 & 70.8 & 4.93 \\
3 & 14.85 & 37.0 & 6.30 & 0.692 & 72.0 & 3.14 \\
4 & 12.14 & 38.6 & 6.90 & 0.693 & 69.3 & 3.31 \\
\hline
\end{tabular}

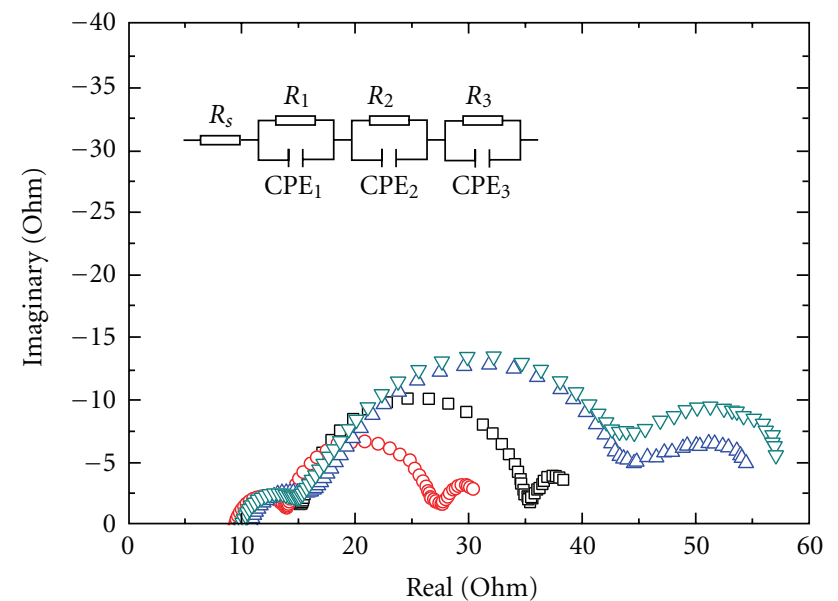

$\begin{array}{ll}\square \text { Sample 1 } & \triangle \text { Sample 3 } \\ \circ \text { Sample 2 } & \nabla \text { Sample 4 }\end{array}$

FIGURE 6: Electrochemical impedance spectra of the DSC devices based on the four samples.

in Figure 5(a), from which we can see that the range of the incident light absorbed by the dye molecules is from about 400 to $750 \mathrm{~nm}$, nearly covering the whole spectrum of visible light. The optical adsorption spectra of these four dye-sensitized photoanodes (see Figure 5(b)) are obtained by subtracting the reflectance spectra of the un-sensitized photoanodes from that of the sensitized ones. As anticipated, the photoanode based on sample 2 exhibits better light adsorption capability than the other three photoanodes. Within the wavelength range from 400 to $600 \mathrm{~nm}$, over $50 \%$ of the incident light can be captured by this photoanode.

3.5. Charge Transport Properties of the DSCs. In order to estimate the resistance of electron transport and charge recombination processes in $\mathrm{ZnO}$-HF-based DSCs, we have measured the electrochemical impedance spectra (EIS) under fixed illumination of $100 \mathrm{~mW} \mathrm{~cm}{ }^{-2}$. The Nyquist plots of the DSCs under open-circuit condition are shown in Figure 6 in which the equivalent circuit of the DSCs is exhibited. As seen from the equivalent circuit, the series resistance $\left(R_{S}\right)$ involves the FTO electrode and external circuit while other three impedance units represent resistances $(R)$ and constant phase elements (CPE). Typically, the diameters of the semicircles (see Figure 6) at high, intermediate, and low frequency ranges represent $R_{1}, R_{2}$, and $R_{3}$, corresponding to the resistances for the charge transfer at the counter electrode, the electron transport/charge recombination at the
$\mathrm{ZnO} /$ electrolyte interface, and the diffusion of $\mathrm{I}_{3}^{-}$ions in the electrolyte, respectively $[33,34]$. According to Figure 6, $R_{S}$ and $R_{1}$ are nearly the same for all four DSC devices, indicating a better repeatability in fabrication of our devices. Because the electron transport resistance is negligible under full sunlight illumination, $R_{2}$ mainly represents the electron recombination resistance at the $\mathrm{ZnO} /$ electrolyte interface. The photoanode made from sample 2 shows the smallest charge recombination resistance $R_{2}$. As mentioned above, HFs in sample 2 have loosely packed nanosheets, porous inner structures, and a large surface area. These structural advantages favor the penetration of the polymer gel electrolyte and then ensure the sufficient contact between the $\mathrm{ZnO}$ surface and electrolyte. Subsequently, the charge transfer at this interface is facilitated and a small $R_{2}$ value is obtained for sample 2 .

\section{Summary}

We have synthesized novel $\mathrm{ZnO}$ HFs in large scale by a facile direct precipitation method at room temperature. The $\mathrm{ZnO} \mathrm{HFs}$ are constructed by interlaced single crystalline nanosheets. The hierarchical structures can be tuned by changing synthesis parameters. We demonstrate that the quasi-solid DSCs fabricated by $\mathrm{ZnO} \mathrm{HFs}$ with porous inner structure show the best photovoltaic performance. We have evidenced that the porous inner construction played an important role for enhancing the DSC's performance because this structure can (1) enrich the internal surface area of the HFs for dye adsorption, (2) efficiently trap incident light inside each individual HF, leading to a better light harvesting capability, and (3) form a $\mathrm{ZnO}$ network with open channels which can largely facilitate electrolyte penetration for the quasi-solid electrolytes.

\section{Acknowledgment}

The authors are grateful for financial support from the Research Grants Council of Hong Kong (Project nos. RPC10SC04, FSGRF12SC22, 603408, 604009).

\section{References}

[1] S. Ito, P. Chen, P. Comte et al., "Fabrication of screenprinting pastes from $\mathrm{TiO}_{2}$ powders for dye-sensitised solar cells," Progress in Photovoltaics, vol. 15, no. 7, pp. 603-612, 2007.

[2] Z. S. Wang, H. Kawauchi, T. Kashima, and H. Arakawa, "Significant influence of $\mathrm{TiO}_{2}$ photoelectrode morphology on the energy conversion efficiency of N719 dye-sensitized solar 
cell," Coordination Chemistry Reviews, vol. 248, no. 13-14, pp. 1381-1389, 2004.

[3] K. D. Benkstein, N. Kopidakis, J. van de Lagemaat, and A. J. Frank, "Influence of the percolation network geometry on electron transport in dye-sensitized titanium dioxide solar cells," Journal of Physical Chemistry B, vol. 107, no. 31, pp. 7759-7767, 2003.

[4] F. Sauvage, D. Chen, P. Comte et al., "Dye-sensitized solar cells employing a single film of mesoporous $\mathrm{TiO}_{2}$ beads achieve power conversion efficiencies over 10\%," ACS Nano, vol. 4, no. 8, pp. 4420-4425, 2010.

[5] G. Redmond, D. Fitzmaurice, and M. Graetzel, "Visible light sensitization by cis-bis(thiocyanato)bis(2,2' -bipyridyl$4,4^{\prime}$-dicarboxylato) ruthenium(II) of a transparent nanocrystalline $\mathrm{ZnO}$ film prepared by sol-gel techniques," Chemistry of Materials, vol. 6, no. 5, pp. 686-691, 1994.

[6] K. Keis, E. Magnusson, H. Lindström, S. E. Lindquist, and A. Hagfeldt, "A 5\% efficient photoelectrochemical solar cell based on nanostructured $\mathrm{ZnO}$ electrodes," Solar Energy Materials and Solar Cells, vol. 73, no. 1, pp. 51-58, 2002.

[7] K. Keis, C. Bauer, G. Boschloo et al., "Nanostructured ZnO electrodes for dye-sensitized solar cell applications," Journal of Photochemistry and Photobiology A, vol. 148, no. 1-3, pp. 5764, 2002.

[8] Z. G. Chen, Y. W. Tang, L. S. Zhang, and L. J. Luo, "Electrodeposited nanoporous $\mathrm{ZnO}$ films exhibiting enhanced performance in dye-sensitized solar cells," Electrochimica Acta, vol. 51, no. 26, pp. 5870-5875, 2006.

[9] Y. T. Shi, C. Zhan, L. D. Wang et al., "Polydisperse spindleshaped $\mathrm{ZnO}$ particles with their packing micropores in the photoanode for highly efficient quasi-solid dye-sensitized solar cells," Advanced Functional Materials, vol. 20, no. 3, pp. 437-444, 2010.

[10] Q. F. Zhang, C. S. Dandeneau, X. Zhou, and C. Cao, "ZnO nanostructures for dye-sensitized solar cells," Advanced Materials, vol. 21, no. 41, pp. 4087-4108, 2009.

[11] A. Kay and M. Grätzel, "Dye-sensitized core-shell nanocrystals: improved efficiency of mesoporous tin oxide electrodes coated with a thin layer of an insulating oxide," Chemistry of Materials, vol. 14, no. 7, pp. 2930-2935, 2002.

[12] T. Stergiopoulos, I. M. Arabatzis, H. Cachet, and P. Falaras, "Photoelectrochemistry at $\mathrm{SnO} 2$ particulate fractal electrodes sensitized by a ruthenium complex solid-state solar cell assembling by incorporating a composite polymer electrolyte," Journal of Photochemistry and Photobiology A, vol. 155, no. 13, pp. 163-170, 2003.

[13] S. Chappel, S. G. Chen, and A. Zaban, "TiO ${ }_{2}$-coated nanoporous $\mathrm{SnO}_{2}$ electrodes for dye-sensitized solar cells," Langmuir, vol. 18, no. 8, pp. 3336-3342, 2002.

[14] N. G. Park, M. G. Kang, K. S. Ryu, K. M. Kim, and S. H. Chang, "Photovoltaic characteristics of dye-sensitized surfacemodified nanocrystalline $\mathrm{SnO}_{2}$ solar cells," Journal of Photochemistry and Photobiology A, vol. 161, no. 2-3, pp. 105-110, 2004.

[15] K. Sayama, H. Sugihara, and H. Arakawa, "Photoelectrochemical properties of a porous $\mathrm{Nb}_{2} \mathrm{O}_{5}$ electrode sensitized by a ruthenium dye," Chemistry of Materials, vol. 10, no. 12, pp. 3825-3832, 1998.

[16] P. Guo and M. A. Aegerter, "RU(II) sensitized $\mathrm{Nb}_{2} \mathrm{O}_{5}$ solar cell made by the sol-gel process," Thin Solid Films, vol. 351, no. 1-2, pp. 290-294, 1999.

[17] T. P. Chou, Q. F. Zhang, G. E. Fryxell, and G. Z. Cao, "Hierarchically structured $\mathrm{ZnO}$ film for dye-sensitized solar cells with enhanced energy conversion efficiency," Advanced Materials, vol. 19, no. 18, pp. 2588-2592, 2007.

[18] E. Hosono, S. Fujihara, and T. Kimura, "Synthesis, structure and photoelectrochemical performance of micro/nanotextured $\mathrm{ZnO}$ /eosin Y electrodes," Electrochimica Acta, vol. 49, no. 14, pp. 2287-2293, 2004.

[19] M. S. Akhtar, M. A. Khan, M. S. Jeon, and O. B. Yang, "Controlled synthesis of various $\mathrm{ZnO}$ nanostructured materials by capping agents-assisted hydrothermal method for dyesensitized solar cells," Electrochimica Acta, vol. 53, no. 27, pp. 7869-7874, 2008.

[20] Q. F. Zhang, T. P. Chou, B. Russo, S. A. Jenekhe, and G. Z. Cao, "Polydisperse aggregates of $\mathrm{ZnO}$ nanocrystallites: a method for energy-conversion-efficiency enhancement in dyesensitized solar cells," Advanced Functional Materials, vol. 18, no. 11, pp. 1654-1660, 2008.

[21] S. H. Ko, D. Lee, H. W. Kang et al., "Nanoforest of hydrothermally grown hierarchical $\mathrm{ZnO}$ nanowires for a high efficiency dye-sensitized solar cell," Nano Letters, vol. 11, no. 2, pp. 666$671,2011$.

[22] Q. F. Zhang, T. P. Chou, B. Russo, S. A. Jenekhe, and G. Z. Cao, "Aggregation of $\mathrm{ZnO}$ nanocrystallites for high conversion efficiency in dye-sensitized solar cells," Angewandte Chemie, vol. 47, no. 13, pp. 2402-2406, 2008.

[23] A. B. F. Martinson, J. W. Elam, J. T. Hupp, and M. J. Pellin, "ZnO nanotube based dye-sensitized solar cells," Nano Letters, vol. 7, no. 8, pp. 2183-2187, 2007.

[24] E. Galoppini, J. Rochford, H. H. Chen et al., "Fast electron transport in metal organic vapor deposition grown dyesensitized $\mathrm{ZnO}$ nanorod solar cells," Journal of Physical Chemistry B, vol. 110, no. 33, pp. 16159-16161, 2006.

[25] M. Guo, P. Diao, X. D. Wang, and S. M. Cai, "The effect of hydrothermal growth temperature on preparation and photoelectrochemical performance of $\mathrm{ZnO}$ nanorod array films," Journal of Solid State Chemistry, vol. 178, no. 10, pp. 3210-3215, 2005.

[26] M. Law, L. E. Greene, J. C. Johnson, R. Saykally, and P. D. Yang, "Nanowire dye-sensitized solar cells," Nature Materials, vol. 4, no. 6, pp. 455-459, 2005.

[27] J. B. Baxter, A. M. Walker, K. van Ommering, and E. S. Aydil, "Synthesis and characterization of $\mathrm{ZnO}$ nanowires and their integration into dye-sensitized solar cells," Nanotechnology, vol. 17, no. 11, pp. S304-S312, 2006.

[28] C. Cheng, Y. Shi, C. Zhu et al., "ZnO hierarchical structures for efficient quasi-solid dye-sensitized solar cells," Physical Chemistry Chemical Physics, vol. 13, no. 22, pp. 10631-10634, 2011.

[29] P. Wang, S. M. Zakeeruddin, J. E. Moser, M. K. Nazeeruddin, T. Sekiguchi, and M. Grätzel, "A stable quasi-solid-state dyesensitized solar cell with an amphiphilic ruthenium sensitizer and polymer gel electrolyte," Nature Materials, vol. 2, no. 6, pp. 402-407, 2003.

[30] P. Wang, S. M. Zakeeruddin, P. Comte, I. Exnar, and M. Grätzel, "Gelation of ionic liquid-based electrolytes with silica nanoparticles for quasi-solid-state dye-sensitized solar cells," Journal of the American Chemical Society, vol. 125, no. 5, pp. 1166-1167, 2003.

[31] Y. T. Shi, C. Zhu, L. Wang et al., "Optimizing nanosheetbased $\mathrm{ZnO}$ hierarchical structure through ultrasonic-assisted precipitation for remarkable photovoltaic enhancement in quasi-solid dye-sensitized solar cells," Journal of Materials Chemistry, vol. 22, no. 26, pp. 13097-13103, 2012. 
[32] F. Xu and L. Sun, "Solution-derived $\mathrm{ZnO}$ nanostructures for photoanodes of dye-sensitized solar cells," Energy and Environmental Science, vol. 4, no. 3, pp. 818-841, 2011.

[33] J. van de Lagemaat, N. G. Park, and A. J. Frank, "Influence of electrical potential distribution, charge transport, and recombination on the photopotential and photocurrent conversion efficiency of dye-sensitized nanocrystalline $\mathrm{TiO}_{2}$ solar cells: a study by electrical impedance and optical modulation techniques," Journal of Physical Chemistry B, vol. 104, no. 9, pp. 2044-2052, 2000.

[34] Q. Wang, J. E. Moser, and M. Grätzel, "Electrochemical impedance spectroscopic analysis of dye-sensitized solar cells," Journal of Physical Chemistry B, vol. 109, no. 31, pp. 1494514953, 2005. 

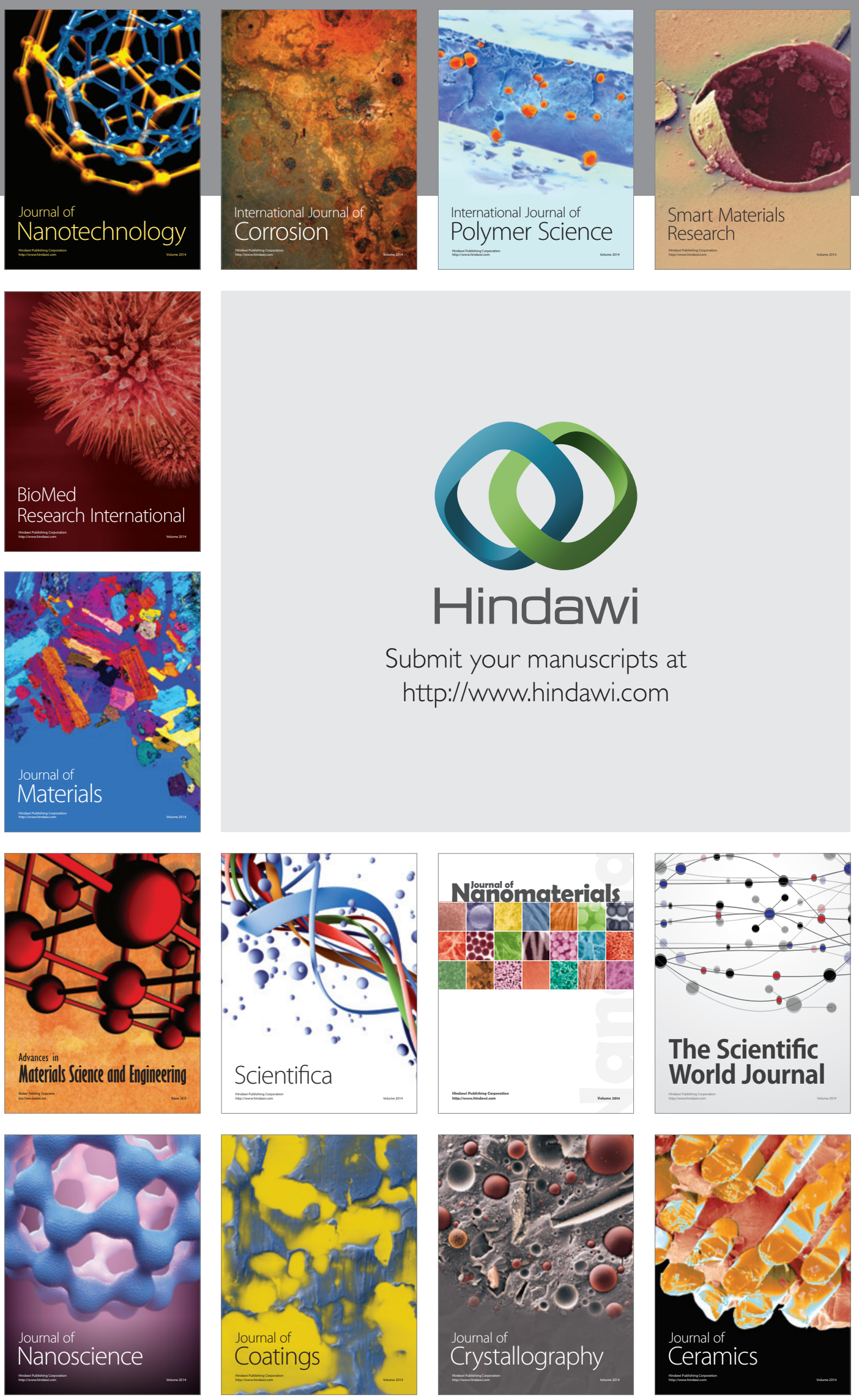

The Scientific World Journal

Submit your manuscripts at

http://www.hindawi.com

\section{World Journal}

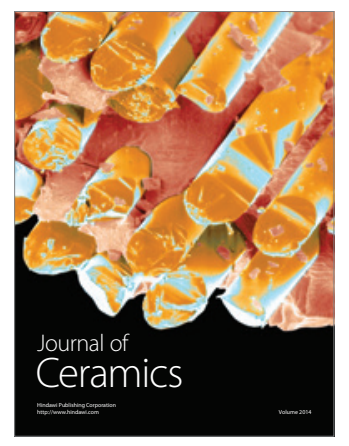

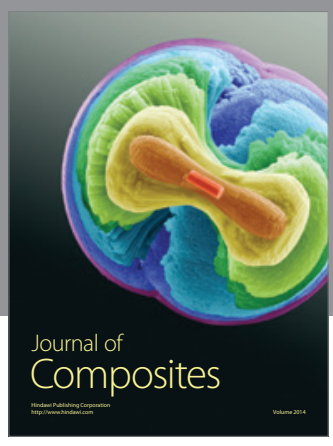
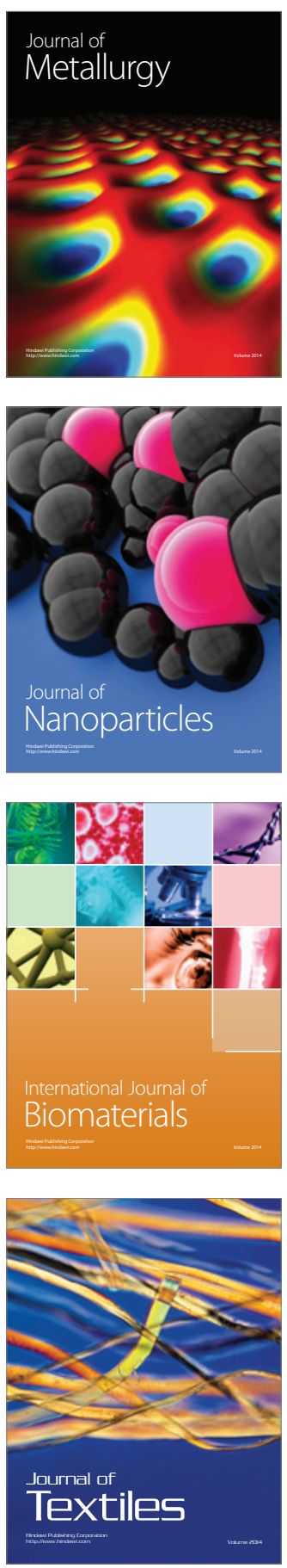